Goldschmidt 2021 Abstract

https://doi.org/10.7185/gold2021.3373

\section{Out of place in the South African rainbow nation: A foreign female geologist's story}

\section{ALBA GÓMEZ-ARIAS AND DR. LUIS ESCOBEDO}

University of the Free State

Presenting Author: albagomezarias1@gmail.com

More than seven years have passed since the first time my categorisation as a woman, my racialization as 'white', and migrant status conflated to make my transition towards life and career in South Africa particularly laborious. It was the beginning of 2014, when my participation in the installation of a semi-passive water treatment plant at pilot scale in North Eastern South Africa demanded from me more than just my knowledge and expertise as a geologist. It exposed me to an intersection of gender-based and linguistic discrimination, racial prejudice, and other issues congruent with 'violent categorisation', where an individual's 'personal internal plurality and complexity are reduced to simplistic interpretations'[1]. However, the incidents of 2014, and those that would come later, constituted an opportunity for me to respond creatively to longstanding global and structural issues, develop or strengthen competences significant to my career and life, and influence and shape my most immediate environment.

In this study, Luis, a researcher on identification, migration and racism, and I, a geologist, engage collectively with my life and migration stories in order to discuss how violent categorisation functions in the physical and symbolic spaces of the field of geology, and what the role of individual agency is in mitigating its material consequences. We approach my presence in geology-related spaces in South Africa as that of a 'body out of place'[2] navigating a particular 'social geography of race'[3] where many middle-class 'white' men often react according to an unreflective 'injured whiteness'[4]. We are interested in how a foreign female geologist can function within the narrative of the 'rainbow nation'. This analysis does not only allow us to challenge said dominant narrative but also brings a new contribution to the literature on female, white, privileged, academic and North-South migration. We hope that this transdisciplinary collaboration also supports future female scientists in the understanding of the complexities entailed in the practice of their careers at a global scale.

[1] Kurzwelly \& Escobedo (2021), Migrants, Thinkers, Storytellers. [2] Ahmed (2000), Strange Encounters. [3] Frankenberg (1993), White Women, Race Matters. [4] Junge, Mitchell, Jarrín \& Cantero (2021), Precarious Democracy.

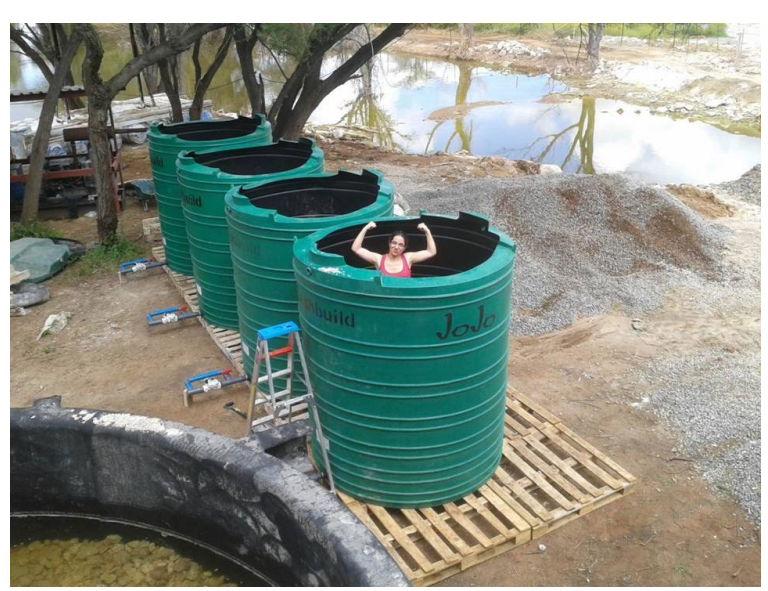

